\section{Effect of Plasma and Fiber Position on Flexural Properties of a Polyethylene Fiber-Reinforced Composite}

Silvana M. M. Spyrides, Maíra do Prado, Renata Antoun Simão, Fernando Luis Bastian
Department of Metallurgic and Materials Engineering, UFRJ Universidade Federal do Rio de Janeiro, Rio de Janeiro, RJ, Brazil

Correspondence: Dra Maíra do Prado, Cid. Universitária - Centro de Tecnologia - Bloco F, sala F-201, llha do Fundão, 21941-972 Rio de Janeiro, RJ, Brazil. Tel: +55-21-39388526. e-mail: maira@metalmat.ufrj.br

\begin{abstract}
The aim of this study was to evaluate the effect of plasma treatment using argon and oxygen gases, combined with fiber position on flexural properties of a fiber-reinforced composite. Eleven groups were evaluated, a non-reinforced control group and 10 groups reinforced with InFibra, a woven polyethylene fiber, varying according to the plasma treatment and fiber position. The samples were prepared using a stainless steel two-piece matrix. The three point bending test was performed in an EMIC testing machine. Flexural strength (FS) and flexural deflection (FD) were calculated from initial (IF) and final (FF) failure. Data were evaluated statistically using Kruskal-Wallis and Mann-Whitney tests $(p<0.05)$. For IF, in all groups with fibers placed on the base, the FS and FD values were significantly higher than those positioned away from the base. The highest value of FS was obtained in the group treated with $03 \mathrm{~min}(296.2 \mathrm{MPa})$ and the highest value of FD was obtained in the group treated with $1 \mathrm{~min}(0.109 \mathrm{~mm})$. For FF the FS and FD values obtained for the groups with fibers positioned away from the base were similar or higher than those placed on the base. The highest FS value was obtained in the group treated with $1 \mathrm{~min}(317.5 \mathrm{MPa})$ and the highest FD value was obtained in the group treated with $03 \mathrm{~min}(0.177 \mathrm{~mm})$. Plasma treatment influenced FS and FD. Fiber position and plasma treatment affected the flexural properties of a fiber-reinforced composite.
\end{abstract}

Key Words: argon plasma, fiber-reinforced composite, fiber position, flexural properties, oxygen plasma.

\section{Introduction}

Fiber-reinforced composite (FRC) restoration has been increasingly indicated and used since its introduction $(1,2)$. It can be used in fixed partial dentures and for periodontal splinting, complete and partial crowns, root posts and orthodontic appliances (3-5). In the prosthodontic area, it's most frequent indication is associated with esthetics, reduced cost and less time required to perform the conservative preparation (6).

Several factors influence the mechanical and physical properties of FRC, including the inherent properties of the fibers, matrix and polymer, fiber surface treatment. In addition to the aforementioned factors, these FRC properties are also affected by the impregnation of fibers with resin, fiber adhesion to the matrix, length and form of fibers, water sorption of resin matrix, fiber volume fraction, and the direction, orientation, location, construction, distribution and position of the fibers $(4,5)$.

High-density polyethylene (HDPE) has been used as fiber-reinforced composite due its chemical resistance, lightweight and superior mechanical strength. Several studies have shown that the HDPE fiber reinforced the FCR and that the fiber position influenced the flexural strength (7).

The HDPE disadvantages are its hydrophobicity and inadequate adhesion. Attempts have been made to improve its adhesion properties using plasma, chemical and radiation treatments to activate the polyethylene surface $(7,8)$.

Plasma treatment is an "effective" and "clean" technology, since the bulk properties of the materials may remain unaltered or well-maintained after the treatment (9). Plasmas are partially ionized gases that contain highly reactive particles, including electronically excited atoms, molecules, ionic and free radical species. Depending on the plasma chemistry or gas composition, these highly reactive plasma species can react with, clean and etch material surfaces, bond to various substrates, or combine to form a thin layer of plasma coating, and consequently alter the surface characteristics of the substrate (10).

Oxygen plasma acts on the surface creating oxygen functional groups, increasing the surface hydrophilicity, whereas argon plasma acts by promoting cross-linking of molecules on polymer surfaces $(7,11-13)$. Lee et al. (7) evaluated the effects of plasma treatment using oxygen, nitrogen and argon gases for $5 \mathrm{~min}$ on the shear behavior of HDPE/steel joints by treating high-density polyethylene (HDPE) and observed improvements in shear strength and the creation of carbonyl functional groups on the HDPE surface by plasma treatments.

Previous studies have evaluated the influence of fiber position on flexural properties $(2,4,5,8)$, however no 
study associated the effect of plasma applied immediately on HDPE fibers in different positions within the fiberreinforced composite with regard to flexural properties. Therefore, the aim of the present study was to evaluate the effect of plasma on a fiber surface immediately after treatment. The tested research hypotheses were: argon and oxygen plasma treatments have no influence on (i) flexural strength, (ii) deflection and (iii) fracture pattern of a fiber-reinforced composite; (iv) the position of fiber treated with plasma has no influence on the flexural properties of a fiber-reinforced composite.

\section{Material and Methods}

In the present study, Signum Ceramis (Heraeus Kulzer, Hanau, Germany) composite and InFibra (Bioloren, Saronno, VA, Italy), a woven polyethylene fiber without any surface treatment, were used. First, 60 samples of polyethylene fiber $(2 \times 25 \mathrm{~mm})$ were made and divided into 10 groups $(n=6)$.

Eleven groups were evaluated: a non-reinforced control group and 10 reinforced groups, according to the plasma treatment and fiber position, as shown in Table 1.

\section{Plasma Treatment}

For plasma treatment, forty-eight fibers were used. Twenty-four fibers were subjected to oxygen and the other 24 to argon plasma treatment. Half of the fibers were treated for $1 \mathrm{~min}$ and the other half for 3 min with 30 W power and $1.2 \times 10^{-1}$ mbar (12 Pa) pressure, in a plasma reactor composed of a tubular borosilicate glass chamber wrapped in a seven copper turns coil. The dimensions of glass tube were $3 \mathrm{~cm}$ diameter and $30 \mathrm{~cm}$ length and the copper coil was $1 \mathrm{~cm}$ (width). Impedance matching with a $13.56 \mathrm{MHz}$ RF power supply was achieved by a variable capacitor matching box. Primary vacuum was achieved using a mechanical pump connected to the upper part of the reactor. Gas was introduced by a needle valve connected to the lower part of the glass tube. Samples were hanged inside the reactor, always in the same position, so that all surfaces of the fibers were exposed to plasma.

\section{Sample Preparation}

Samples were prepared according to ISO 4049:2000(E). A two-piece stainless steel matrix $(2 \times 2 \times 25 \mathrm{~mm})$ was used to prepare the specimens. For the non-reinforced test specimens, the matrix was filled with a single increment of Signum material.

For the reinforced test specimens, all the fibers were impregnated with Connect Resin before sample preparation.

In the specimens with fibers positioned on the base (Fig. 1A), a single layer of fibers was initially placed, and then the matrix was filled with Signum material. Photo activation was initially carried out with a manual high power Led Radii photo activator (SDI Brasil Industria e Comercio Ltda, São Paulo, SP, Brazil), in ten 20 s steps, five at the top and five at the base, with the first in the center and the remaining steps alternating to the right and left side until the edge of the specimen was reached. After this, the specimen was removed from the forming matrix and taken to the UniXS (Heraeus Kulzer) unit for photo activation for $180 \mathrm{~s}$.

Table 1. Experimental groups

\begin{tabular}{|c|c|}
\hline Groups $(n=6)$ & Composite/ Fiber treatment/ Fiber position \\
\hline 1 & Signum \\
\hline 2 & Signum/lnFibra/ on the base \\
\hline 3 & Signum $/ \operatorname{lnFibra~} \mathrm{O}_{2} 1 \mathrm{~min} /$ on the base \\
\hline 4 & Signum $/ \mathrm{lnFibra} \mathrm{O}_{2} 3 \mathrm{~min} /$ on the base \\
\hline 5 & Signum/lnFibra /Ar $1 \mathrm{~min} /$ on the base \\
\hline 6 & Signum/lnFibra $/$ Ar $3 \mathrm{~min} / \mathrm{on}$ the base \\
\hline 7 & Signum/InFibra/ away from the base \\
\hline 8 & Signum/lnFibra $\mathrm{O}_{2} 1 \mathrm{~min} /$ away from the base \\
\hline 9 & Signum/lnFibra $\mathrm{O}_{2} 3 \mathrm{~min} /$ away from the base \\
\hline 10 & Signum/lnFibra $/$ Ar $1 \mathrm{~min} /$ away from the base \\
\hline 11 & Signum/lnFibra /Ar $3 \mathrm{~min} /$ away from the base \\
\hline
\end{tabular}

$\mathrm{O}_{2}$ : oxygen plasma; Ar: argon plasma.

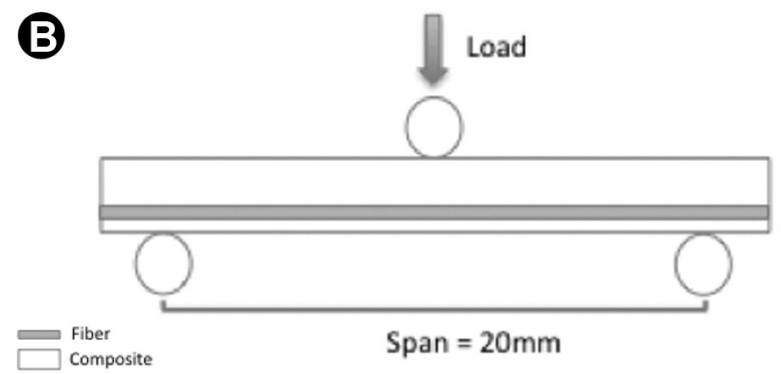

Figure 1. Schematic image showing the fiber position on the base (A) and away from the base (B). 
In the reinforced test specimens with fibers positioned away from the base (Fig. 1B) a thin layer $(0.3 \mathrm{~mm})$ of Signum was introduced on the base of the matrix. Then the single layer of fibers was placed and the matrix was completely filled with Signum material. Photo activation was carried out as described above. All the test specimens were subjected to manual sanding with 600-grit sandpaper and stored in distilled water at $37^{\circ} \mathrm{C}$ for $24 \mathrm{~h}$.

\section{Flexural Tests}

The three point bending test was conducted according to ISO 4049:2000(E) in a testing machine (test span: 20 $\mathrm{mm}$, crosshead speed of $0.5 \mathrm{~mm} / \mathrm{min}$; EMIC DL 2000; EMIC, São José dos Pinhais, PR, Brasil). Load-displacement curves were recorded with a PC-computer software program (Tesc, v. 1.10, EMIC).

From the results of the flexural tests it was possible to calculate the flexural strength and flexural deflection using the following equations:

$$
\sigma=\frac{3 P l}{2 b h^{2}}
$$

where $\sigma$ is the flexural strength, I the span length between the supports, $b$ the width of the sample, $h$ the height of the sample and $P$ the fracture load.

$$
D=\frac{d}{l}
$$

Where $D$ is the deflection, $d$ the flexure displacement and I the span length between supports.

As regards failure, initial failure (IF) was considered to occur at the first load drop higher than $1 \%$ on the load displacement curve, in accordance with the recommendation of the Fracture Mechanics Toughness Tests Standard BS 7448 Part 1: $1991(14,15)$ for critical loads in materials presenting pop-ins. The final failure (FF) of the specimen was characterized as the maximal load before the load decreased by $50 \%$, or an obvious catastrophic rupture (7). The experiments were accompanied in real-time and the images of failure were qualitatively evaluated.

\section{Statistical Analysis}

To test the data normality, Kolmogorov-Smirnov test was used. Since the data did not follow a normal distribution (normality), statistical analysis was carried out using the nonparametric Kruskal-Wallis and Mann-Whitney tests $(p<0.05)$.

\section{Results}

Figure 2 shows the flexural strength results. In the groups where the fibers were placed on the base, the initial and final failure values were close, while for fibers placed away from the base, the values were widely spread. With respect to initial failure, samples with fibers on the base showed significantly higher values than those with fibers away from the base. Additionally, the presence of fiber away from the base showed lower flexural strength values than those of the composite alone. On the other hand, in the final failure, this behavior differed, i.e. samples with fibers placed on the base showed values lower than, or similar to those of samples with fibers placed away from the base.

With respect to the effect of plasma treatment, when evaluating initial failure, oxygen treatment for 1 and 3 min, and argon plasma treatment for 3 min significantly improved the flexural strength values of the samples with fibers on the base. Argon 1 min showed results similar to those of the reinforced composite, and higher than those of the composite alone. Placed away from the base, the
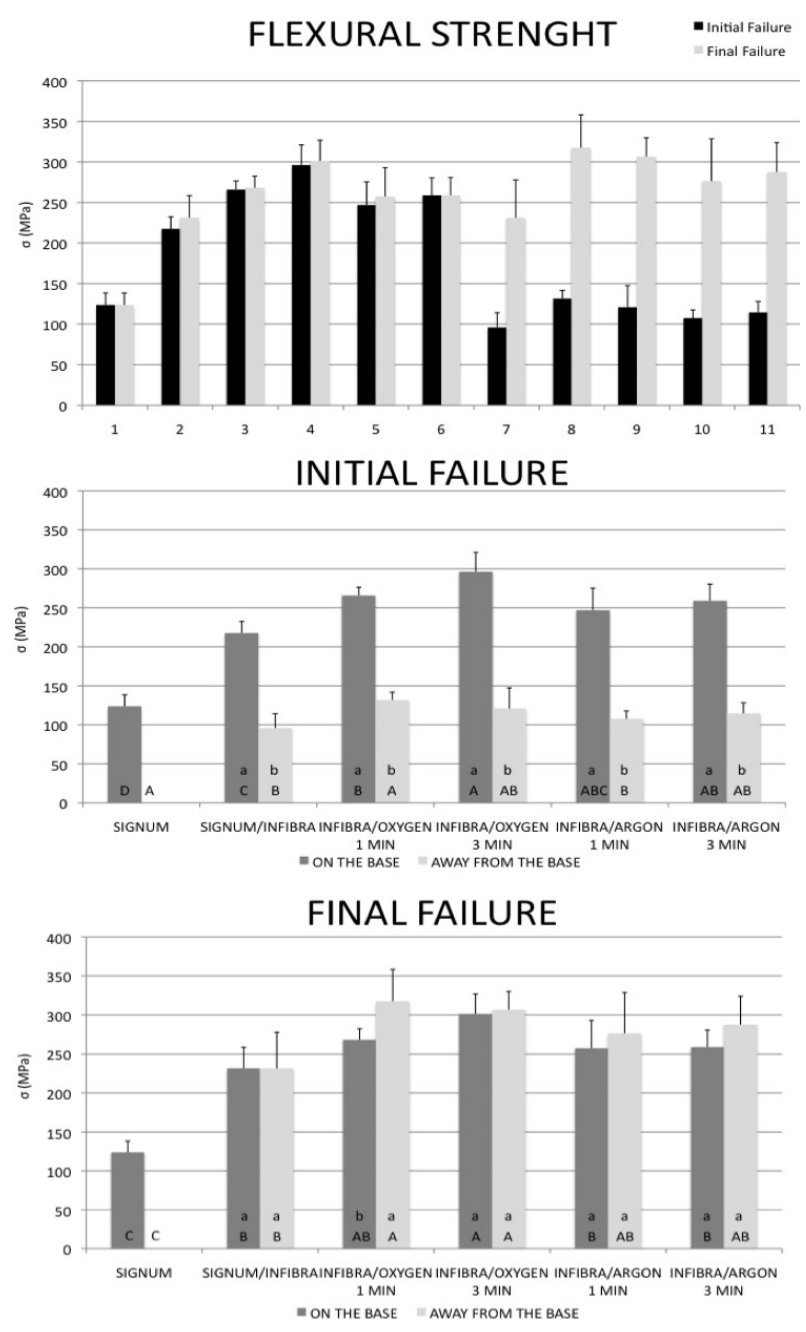

Figure 2. Flexural strength of the different groups with: no fiber, fiber placed on the base and away from the base. Note: The superscript dark gray capital letters indicate statistically significant values $(p<0.05)$, for plasma treatment with fibers placed on the base. The superscript light gray capital letters indicate statistically significant values $(p<0.05)$, for plasma treatment with fibers placed away from the base. The superscript lowercase letters indicate statistically significant values $(p<0.05)$, when comparing fibers placed on the base with those placed away from the base. 
untreated fibers were not favorable to flexural strength. However, some of the plasma treatments (oxygen 1 and 3 $\mathrm{min}$ and argon $3 \mathrm{~min}$ ) improved the flexural strength values in comparison with those of the untreated fibers, showing results similar to those of the composite. As regards final failure, oxygen plasma for 1 and 3 min improved the flexural strength values for samples with the fibers away from the base. However, when fibers were placed on the base, only oxygen plasma for 3 min showed significant increase in FS.

Figure 3 shows the flexural deflection findings of the groups. Comparing the groups with fibers on the base with those with fibers away from the base, the results were similar to those for flexural strength, i.e. the initial and final failure values were close in samples with fibers placed on the base, but when fibers were away from the base, the values were widely spread.

With regard to plasma effect on initial failure, for the groups with fibers on the base, only oxygen plasma (1 $\min$ ) favored flexural deflection. When fibers were away
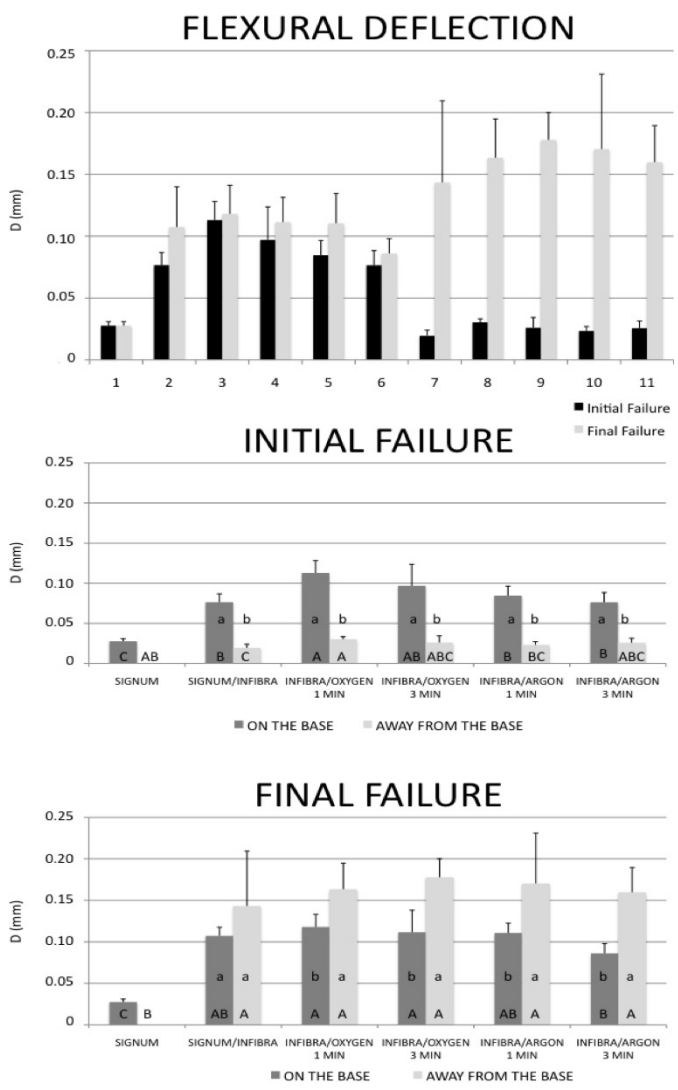

Figure 3. Flexural deflection of the different groups with: no fiber, fiber placed on base and away from the base. Note: The superscript dark gray capital letters indicate statistically significant values $(p<0.05)$, for plasma treatment with fibers placed on the base. The superscript light gray capital letters indicate statistically significant values $(p<0.05)$, for plasma treatment with fibers placed away from the base. The superscript lowercase letters indicate statistically significant values $(p<0.05)$, when comparing fibers placed on the base with those placed away from the base. from the base, plasma treatments showed results similar to those of the composite. As regards final deflection, plasma treatment did not show better results than those obtained with untreated fiber.

Figure 4 shows pictures of the real-time experiment with respect to failure pattern. In the cases where fibers were on the base (Figs. 4A and 4B), irrespective of plasma treatment or not, cracks were observed in composite, in the area at the center of sample where load was applied. Subsequently, a shear failure occurred on one side of the sample. In the case of fibers placed away from the base, in the untreated fiber group and argon 1 min group (Fig. 4C) cracks were observed in the composite below the fiber, and subsequently above the fiber, followed by a shear failure on one of the upper sides of the fiber. After oxygen plasma 1- and 3-min and argon plasma 3-min treatments (Fig. 4D), cracks initially occurred in composite below the fiber, which could or not be followed by cracks in the composite above the fiber. In these groups no shear failure was observed.

\section{Discussion}

Polyethylene fibers can be drawn as mono-filament fibers and woven into fabrics. They can either be treated with plasma, or not. Plasma is used to enhance the adhesion between polyethylene and resins, by chemically etching or modifying the fiber surface $(8,16)$. However, the manufacturers do not reveal the gas used for this purpose. Due to the fact that plasma treatment progressively loses its effectiveness as time passes (17), the present study evaluated the effect of plasma on a fiber surface immediately after treatment, using the three-point bending test. This test was used to evaluate the flexural properties, because it is more relevant clinically, as masticatory forces are normally concentrated on a single point $(8,18)$.

In the present study, evaluation of the non-reinforced composite (Group 1) with addition of polyethylene fibers resulted in significant enhancement of the flexural performance when fibers were placed on the base. All the reinforced groups presented an elasto-plastic behavior, and remained bonded during testing. Catastrophic failure took place only in Group 1. These results are in agreement with results of several other studies $(2,5,8,19-21)$.

In the groups with fibers on the base, the initial and final failure FS values were close. This occurred because, for initial failure, the sample reached a high level of stress and deformation and it was unable to absorb much more energy until final failure. On the other hand, in the group with fibers away from the base, the values were widely spread. This behavior can be explained by the fact that cracks occurred in the composite below the fiber. In each crack a partial loss of load occurred, leading to partial energy dissipation. Relief of the load allows the material 
to support a new uploading, with energy dissipation and growth of new cracks, in a successive process.

The groups reinforced with fiber on the base showed higher values for flexural properties at the initial failure, than those of the non-reinforced composite. These results are in agreement with the results of several other studies $(2,5)$. On the other hand, when fibers were placed away from the base, the composite reinforced with non-treated polyethylene fiber showed lower values for flexural properties than those of the composite alone. This may be attributed to the fact that the surface of polyethylene fiber is nonpolar, making difficult its adherence to the particulate composite, thereby acting as a non-adherent surface or as a defect. This is in contrast to the findings of Ellakwa et al. (8). Moreover, Dyer et al. (5) observed lower load values of reinforced composite than those of non-reinforced composite and Ellakwa et al. (2) found no statistical differences in FS between non-reinforced and reinforced composites with fiber away from the base.

With regard to the plasma treatments, samples with fibers on the base and treatment with oxygen 1 and 3 min and argon $3 \mathrm{~min}$, showed an increase in flexural strength values, when compared with non-treated fiber, in the initial failure. For final failure, only oxygen plasma 3-min treatment exhibited a significant improvement in the flexural strength. These results may be attributed to the surface changes produced by plasma treatment as higher wettability, size of the rough surface structure (including pit depth ratio and aspect) and density of chemical bonds per unit area between fiber and resin (2224). Additionally, according to Lee et al. (7) treating the surface of polyethylene with plasma promotes an increase in surface roughness and incorporation of carbonyl functional groups and oxygen plasma is more effective than the argon plasma to improve bonding strength.

In samples with fibers away from the base, at the initial failure, plasma treatments showed flexural strength and deflection results similar to those of composite, but they were never superior. On the other hand, plasma treatment significantly improved flexural strength at the final failure.
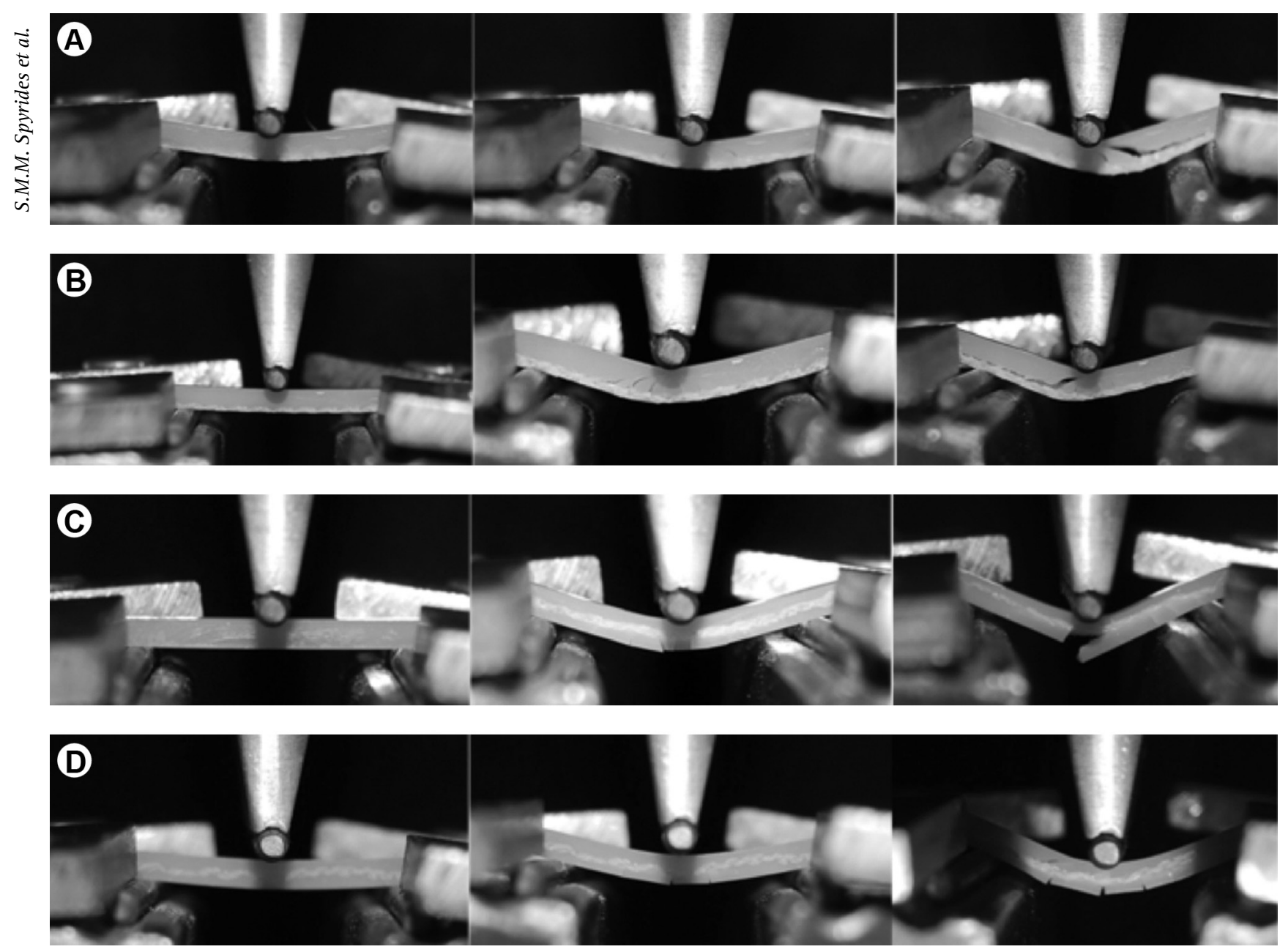

Figure 4. Images of initial, middle and end of flexural test. Representative of the cases of fibers placed on the base, without (A) and with plasma treatment (B), and placed away from the base, without (C) and with plasma treatment (D). 
Therefore, the initial failure may be a more sensitive or useful indicator of material integrity for possible clinical interpretation than the final failure (5).

Comparing the results of fiber position with regard to flexural properties, fibers on the base showed superior results to those of fibers away from the base, in the initial failure. These results are in agreement with those of Ellakwa et al. (2) and Dyer et al. (5) but differ from the findings of Ellakwa et al. (8), who found no significant differences comparing the fibers on the base with those away from the base.

As regards fibers away from the base, in the groups with untreated fibers and those treated with argon plasma 1 min (Fig. 4c) cracks were observed in the composite below the fiber, and subsequently above the fiber, followed by a shear failure on one of the upper sides of the fiber. The larger number of cracks in the samples with fibers away from the base has previously been reported by Ellakwa et al. (8). After plasma treatments with oxygen and argon for 3 min (Fig. 4D), cracks initially occurred in composite below the fiber, which could be or not accompanied by cracks above the fiber. Several cracks were created below the fiber, allowing it to stretch, so that shear failure did not occur. Despite the several cracks, the fragments remained bonded. This result can be attributed to the surface changes produced by plasma treatment $(7,21,25)$.

Clinically, the initial failure can produce undesirable effects such as saliva infiltration, reducing the lifetime of the prosthesis. Thus, the initial failure is a more usual and important indicator for the purpose of resistance calculation than the ultimate failure of the material (5). Although a high deflection is an important aspect of composites generally, clinically this behavior is not ideal. Higher deflection could injure the patient's gingival mucosa. In view of these facts, the present study revealed that fiber should be placed on the base. As regards fiber treatment, oxygen and argon plasma treatment for 3 min were the best because they provided higher flexural strength associated with lower deflection.

The present study revealed that the fiber position affected the flexural properties of a fiber-reinforced composite. Plasma treatment improved the flexural properties of a fiber-reinforced composite with the fiber located on the base. Other studies using different gases with the aim to reduce the periods of plasma application, as well as tests simulating clinical conditions are important to validate this technology in clinical environment.

\section{Resumo}

0 objetivo deste estudo foi avaliar o efeito do tratamento de plasma, utilizando os gases argônio e oxigênio, associado à posição da fibra, nas propriedades mecânicas de um compósito reforçado por fibra. Onze grupos foram avaliados, um grupo controle, sem reforço, e 10 grupos reforçados com Infibra, variando de acordo com o tratamento de plasma e a posição das fibra. As amostras foram preparadas utilizando uma matriz bipartida de aço inoxidável. 0 teste de flexão de três pontos foi realizado em uma máquina de ensaios EMIC. A resistência à flexão (FS) e deflexão (FD) foram calculados em relação à falha inicial (IF) e final (FF). Os dados foram avaliados estatisticamente pelos testes de Mann-Whitney e Kruskal-Wallis $(p<0,05)$. Para IF, nas fibras posicionadas na base, os valores de FS e FD foram significativamente maiores do que quando as fibras foram afastadas da base em todos os grupos. 0 maior valor de FS foi obtido no grupo tratado com $03 \mathrm{~min}(296,2 \mathrm{MPa})$ e o maior valor de FD foi obtido no grupo tratado com $01 \mathrm{~min}(0,109 \mathrm{~mm})$. Para FF, os valores de FS e FD para os grupos com fibras afastadas da base foram semelhantes ou superiores aos daqueles com fibras na base. 0 maior valor de FS foi obtido no grupo tratado com $01 \min (317,5 \mathrm{MPa})$ e o maior valor de FD foi obtido no grupo tratado com $03 \mathrm{~min}(0,177 \mathrm{~mm})$. 0 tratamento de plasma influenciou o FS e o FD. A posição de fibras, assim como o tratamento de plasma, afetaram as propriedades de flexão de um compósito reforçado com fibra.

\section{Acknowledgements}

Supported by the Brazilian agencies: CAPES (Grant \#2642/2014; PNPD), FAPERJ (Grant \#E-26/111.081/2013) and CNPq (Grant \#485263/20130 ). The authors would like to thank Heraeus Kulzer for supplying the Signum material.

\section{References}

1. Leinfelder K. Advances in biorestorative materials. J Am Dent Assoc 2000;131:35-41.

2. Ellakwa A, Shortall A, Marquis P. Influence of fibre position on the flexural properties and strain energy of a fibre-reinforced composite. J Oral Rehabil 2003;30:679-682.

3. Waki T, Nakamura T, Nakamura T, Kinuta S, Wakabayashi K, Yatani H. Fracture resistance of inlay-retained fixed partial dentures reinforced with fiber-reinforced composite. Dent Mater J 2006;25:1-6

4. Rashidan N, Esmaeili V, Alikhasi M, Yasini S. Model system for measuring the effects of position and curvature of fiber reinforcement within a dental composite. J Prosthodont 2010;19:274-278.

5. Dyer SR, Lassila LV, Jokinen M, Vallittu PK. Effect of fiber position and orientation on fracture load of fiber-reinforced composite. Dent Mater 2004;20:947-955.

6. Sharafeddin F, Alavi A, Talei Z. Flexural strength of glass and polyethylene fiber combined with three different composites. J Dent (Shiraz) 2013;14:13-19.

7. Lee JH, Rhee KY, Lee JH. Effects of reactive gas on shear and fracture behaviors of plasma-treated polyethylene/steel joints. Appl Surf Sci 2009;256:876-883.

8. Ellakwa $A E$, Shortall $A C$, Shehata $M K$, Marquis PM. The influence of fibre placement and position on the efficiency of reinforcement of fibre reinforced composite bridgework. J Oral Rehabil 2001;28:785791.

9. Chen M, Zhang Y, Sky Driver M, Caruso AN, Yu Q, Wang Y. Surface modification of several dental substrates by non-thermal, atmospheric plasma brush. Dent Mater 2013;29:871-880.

10. Ritts AC, Li H, Yu O, Xu C, Yao X, Hong L, et al.. Dentin surface treatment using a non-thermal argon plasma brush for interfacial bonding improvement in composite restoration. Eur J Oral Sci 2010;118:510516.

11. Yu HY, He XC, Liu LQ, Gu JS, Wei XW. Surface modification of poly(propylene) microporous membrane to improve its antifouling characteristics in an SMBR: 02 plasma treatment. Plasma Proc Polym 2008;5:84-91.

12. Shi $L S$, Wang $L Y$, Wang $Y N$. The investigation of argon plasma surface modification to polyethylene: quantitative ATR-FTIR spectroscopic analysis. Eur Polymer J 2006;42:1625-1633.

13. Yao YG, Liu XS, Zhu YF. The influence of the surface cross-linking of 
the high density polyethylene induced by plasma treatment on the durability of treatment efficiency. J Appl Polym Sci 1993;48:57-65.

14. ASTM E 1820. Standard test methods for measurement of fracture toughness. In: Annual Book of ASTM Standards, Vol 3.01. American Society for Testing and Materials, Philadelphia; 1999.

15. Castrodeza EM, Rodrigues Touça JM, Perez JE, Perez Ipiña JE, Bastian FL. Determination of CTODC in fibre metal laminates by ASTM and Schwalbe methods. Mat Res 2002;5:119-124.

16. Jagger DC, Harrison A, Jandt KD. The reinforcement of dentures. J Oral Rehabil 1999;26:185-194.

17. Ozden N, Akaltan F, Suzer S, Akovali G. Time-related wettability characteristic of acrylic resin surfaces treated by glow discharge. J Prosthet Dent 1999;82:680-684.

18. Purslow D. Fractography of fibre-reinforced thermoplastics, Part 3. Tensile, compressive and flexural failures. Composites 1988;19:358366.

19. Karbhari VM, Wang Q. Influence of triaxial braid denier on ribbonbased fiber reinforced dental composites. Dent Mater 2007;23:969976.

20. Karbhari VM, Strassler H. Effect of fiber architecture on flexural characteristics and fracture of fiber-reinforced dental composites. Dent Mater 2007;23:960-968.

21. Ellakwa A, Shortall A, Shehata M, Marquis P. Influence of veneering composite composition on the efficacy of fiber-reinforced restorations (FRR). Oper Dent 2001;26:467-475.

22. Moon SI, Jang J. Factors affecting the interfacial adhesion of ultrahighmodulus polyethylene fibre-vinylester composites using gas plasma treatment. J Mater Sci 1998;33:3419-3425.

23. Tissington $B$, Pollard G, Ward IM. A study of the influence of fibre/ resin adhesion on the mechanical behavior of ultra-high-modulus polyethylene fibre composites. J Mater Sci 1991;26:82-92.

24. Nardin $M$, Ward IM. Influence of surface treatment on adhesion of polyethylene fibres. Mater Sci Technol 1987;3:814-826.

25. Tosun K, Burak F, Bülent B. Multiple cracking response of plasma treated polyethylene fiber reinforced cementitious composites under flexural loading. Cem Concr Res 2012;34:508-520.

Received April 25, 2015

Accepted July 18, 2015 